\title{
Accuracy of food intake reporting in obese subjects with metabolic risk factors
}

\author{
Mette Svendsen* and Serena Tonstad \\ Department of Preventive Cardiology, Ullevål University Hospital, N-0047 Oslo, Norway \\ (Received 4 May 2005 - Revised 13 October 2005 - Accepted 7 November 2005)
}

\begin{abstract}
The aim of the present study was to determine the accuracy of reported energy intake according to a food-frequency questionnaire (FFQ) and dietary records (DR) in obese subjects with metabolic syndrome risk factors. Subjects were twenty-three men and twenty-seven women with mean BMI of 35.7 (range $30.5-43.8) \mathrm{kg} / \mathrm{m}^{2}$ who participated in a dietary interview based on a FFQ and completed weighed DR. Total energy expenditure was measured with the doubly labelled water method. Total energy expenditure, measured RMR and physical activity level did not differ between under-reporters $(50 \%$ of the sample) and non-under-reporters. Under-reporters had lower median intake of sweets, desserts and snacks than non-under-reporters $(100 \mathrm{v} .161 \mathrm{~g} / \mathrm{d}$ $(P=0.0008)$ and $61 v .128 \mathrm{~g} / \mathrm{d}(P=0.0002)$ according to the FFQ and DR, respectively). The DR also showed lower energy density (6.7 (SD 1.3$) v .7 .9$ (SD 1.6$) \mathrm{kJ} / \mathrm{g} ; P=0.0064)$, lower intake of sugary drinks $(0 v .167 \mathrm{~g} / \mathrm{d} ; P=0.0063)$ and higher scores for dietary restraint (9.0 (SD 5.0) v. 6.1 (SD 3.5); $P=0.0285)$ in under-reporters. Energy density was associated with accuracy according to the FFQ (Spearman's rank correlation coefficient $\left(R_{\mathrm{S}}\right) 0.406$; $P=0.0034)$ and the DR $\left(R_{\mathrm{S}} 0.537 ; P<0.0001\right)$. In multivariate analysis, consumption of bread and sweets, desserts and snacks measured by the FFQ was positively associated with accuracy $\left(R_{\text {adjusted }}^{2} 0.46(95 \%\right.$ CI $0.32,0.70)$ ). According to the DR, consumption of sweets, desserts and snacks was also associated with accuracy, as was dietary restraint (inversely) $\left(R_{\text {adjusted }}^{2} 0.67\right.$ (95\% CI 0.54, 0.83)). In obese subjects with metabolic risk factors, intake of sweets, desserts and snacks, bread and dietary restraint were determinants of reporting accuracy.
\end{abstract}

Energy intake: Under-reporting: Eating behaviour: Doubly labelled water

In 2001, the National Cholesterol Education Program defined the metabolic syndrome as a constellation of at least three of five risk factors (increased waist circumference, hypertriacylglycerolaemia, low HDL-cholesterol, high blood pressure, and high fasting glucose) that increase the risk of CHD and recommended that the metabolic syndrome should be a target of risk-reduction therapy after the primary target, level of LDL-cholesterol, is met (Expert Panel on Detection, Evaluation, and Treatment of High Blood Cholesterol in Adults, 2001). One of the primary methods of risk reduction is weight loss. Studies have shown that even a modest degree of weight loss induced by dietary and lifestyle change in individuals with characteristics of the metabolic syndrome is associated with clinical benefits (Tuomilehto et al. 2001). However, counselling for weight loss is hampered by the difficulty in obtaining accurate dietary data (Lissner, 2002). The development of the doubly labelled water (DLW) method to estimate total energy expenditure (TEE) has led to general acceptance of the notion that dietary self-reporting substantially underestimates energy intake (EI), and data have accumulated for nearly two decades showing that obese individuals are more likely to under-report than others (Prentice et al. 1986, 1996; Braam et al. 1998; Hill \& Davies, 2001).

Studies on the accuracy of dietary self-reporting have considered a number of factors in addition to a high BMI that may influence the likelihood of under-reporting. These include sex, age, socio-economic status, eating behaviour and dieting, physical activity, non-smoking, psychological factors and the cultural context as reviewed recently (Livingstone \& Black, 2003). Underreporting is accentuated when repeated assessment of dietary intake is conducted (Caan et al. 2004). Furthermore, certain foods and nutrients are more likely to be under-reported than others, primarily carbohydrates, fats, snacks, and foods or drinks that are considered to be unhealthy (Bingham et al. 1995; Heitmann \& Lissner, 1995; Poppitt et al. 1998; Tonstad et al. 1999; Goris et al. 2000; Hill \& Davies, 2001). Such selective under-reporting may lead to spurious associations between dietary components and biological markers or risk factors (Lissner et al. 1998). Poor accuracy of dietary data may be more pronounced and may mislead public policy, in particular when subjects at high risk for disease are considered, for example, individuals with the metabolic syndrome, as indeed has been demonstrated recently (Rosell et al. 2003). In this study, underreporters had a higher prevalence of the metabolic syndrome than other subjects and associations between the diet and the components of the metabolic syndrome differed between under-reporters and the remaining subjects (Rosell et al. 2003).

The aim of the present investigation was to examine the determinants of self-reporting of energy in a sample of obese men and women with the metabolic syndrome or at least two of its risk factors and to explore the specific foods, eating patterns and behaviour that are associated with under-reporting using the DLW method to estimate TEE. The overall goal was to inform 
the dietary advice that is appropriate for this group of individuals. Because cigarette smoking may confound the relationship between nutrient intakes and under-reporting (Dallongeville et al. 1998), we chose to include only non-smokers in the study.

\section{Subjects and methods}

Subjects

Fifty non-smoking, obese men and women with a mean age of 43.2 (SD 10.3; range 24-64) years and a mean BMI of 35.7 (SD 3.3; range $30.5-43 \cdot 8) \mathrm{kg} / \mathrm{m}^{2}$ and two or more risk factors for the metabolic syndrome according to the National Cholesterol Education Program (glucose $\geq 6.1 \mathrm{mmol} / \mathrm{l}$ or HDL-cholesterol $\leq 1.03 \mathrm{mmol} / 1$ for males or $\leq 1.29 \mathrm{mmol} / 1$ for females or serum triacylglycerols $\geq 1.69 \mathrm{mmol} / \mathrm{l}$ or waist circumference $>102 \mathrm{~cm}$ for males or $>88 \mathrm{~cm}$ for females or systolic blood pressure $\geq 130 \mathrm{mmHg}$ and diastolic blood pressure $\geq 85 \mathrm{mmHg}$ ) were recruited by newspaper advertisement and referral to the Department of Preventive Cardiology at Ullevål University Hospital (Oslo, Norway). Subjects were screened via blood chemistry and a medical examination done by a physician to assess risk factors and eligibility to the study. Fifteen subjects had two risk factors, twenty-seven subjects had three risk factors and eight subjects had four risk factors; thus $60 \%$ had the full metabolic syndrome. Exclusion criteria were body weight $>135 \mathrm{~kg}$, current dieting, cigarette smoking, history of eating disorder or chronic disease, suspected non-compliance due to abuse of drugs or alcohol, drug- or insulin-treated diabetes mellitus, migraine requiring intermittent medication, use of thyroxin, diuretics or weight-reducing agents and use of inhaled or oral $\beta$-agonists or corticosteroids. The educational level of each subject was determined according to the number of years of education and categorised as completed primary school, high school or a university degree. The Ethical Committee (region 1 in Norway) approved the protocol and all participants gave their written informed consent. The study was conducted between October 2001 and October 2003.

\section{Measurements}

Height was measured with a standardised wall measuring stick scale to the nearest $0.5 \mathrm{~cm}$. Subjects were weighed (in underwear) with a digital weight (SECA, Hamburg, Germany) to the nearest $0.1 \mathrm{~kg}$. Weight was measured at the screening and baseline visits and on day 1 and day 15 of the DLW measurement period. Weight changes during the DLW period were calculated as the difference between day 15 and day 1 and weight changes during the 3-month study as the difference between day 15 of the DLW period and baseline. Waist was measured in the standing position at the level of umbilicus (unclothed) and hip circumference was measured at the level of the greater trochanter. Body composition was determined by dual-energy X-ray absorptiometry (Lunar Expert 1116; Lunar Corp., Madison, WI, USA). The measurement was done in $15 \mathrm{~min}$. The $\mathrm{CV}$ for the dual-energy $\mathrm{X}$-ray absorptiometry measurements was $3-4 \%$. RMR was measured with a standard portable ventilated hood system (Deltatrac ${ }^{\circledR}$ Metabolic Monitor; Datex Instrumentarium Corp., Helsinki, Finland). The Deltatrac ${ }^{\circledR}$ was calibrated by automatic standard gas calibration at the start of each measurement. The subjects slept at home the night before the measurement. On the day of the measurement the subjects took a taxi to the site. The subjects fasted during the last $12 \mathrm{~h}$ before the measurement and were instructed not to eat or drink anything but water on the day of the measurement. After changing clothes and mounting the equipment, the subjects relaxed for $30 \mathrm{~min}$ in the recumbent position before the head was covered with the canopy. Measurements were done at $1 \mathrm{~min}$ intervals for $20-25 \mathrm{~min}$. A mean value of at least a $10 \mathrm{~min}$ period at a stable level of energy expenditure was defined to be the RMR.

\section{Doubly labelled water method}

Energy expenditure by the DLW method was measured over a period of $14 \mathrm{~d}$ and used as a measure of habitual energy expenditure. Sample analyses and calculation procedures have been described in detail elsewhere (Slinde et al. 2003). First a baseline urine sample was collected for the determination of the background isotope enrichment (day 1). Then a weighed mixture of ${ }^{2} \mathrm{H}$-labelled and oxygenated water, corresponding to $0.05 \mathrm{~g}{ }^{2} \mathrm{H}-$ labelled water and $0.10 \mathrm{~g}{ }^{18} \mathrm{O}$-labelled water $/ \mathrm{kg}$ body weight, was ingested. The percentage enrichment of the waters was $99.9 \%$ for ${ }^{2} \mathrm{H}$ and $10.0 \%$ for ${ }^{18} \mathrm{O}$. The dose was planned to enrich body water with approximately 350 parts per thousand $(\delta$ per mil) for ${ }^{2} \mathrm{H}$ and 60 parts per thousand ( $\delta$ per mil) for ${ }^{18} \mathrm{O}$. Urine samples were collected from the second voiding during day 2 , day 3 , day 4 , day 8 , day 13 , day 14 and day 15 . The mean time interval between drinking dose and the first post-dose urine sample was 22 (SD 3; range 12-30) h. The participants were instructed to collect the urine spot, register exact voiding time and freeze the samples at home. Participants were called every voiding day to ensure compliance with the procedure. When the samplings were completed, the urine samples were stored at $-75^{\circ} \mathrm{C}$ until transportation to the laboratory on dry ice.

Analysis of the isotopic enrichment was determined in triplicates with a Thermoquest Finnigan MAT Delta plus isotoperatio mass spectrometer with a water $/ \mathrm{H}_{2}-\mathrm{CO}_{2}$ equilibrating device (Thermoquest Finnigan MAT, Bremen, Germany). The precision defined as standard error in triplicate samples is 0.26 for ${ }^{3} \mathrm{H}$ and 0.10 for ${ }^{18} \mathrm{O}$. Tap water was collected and analysed for background measurements and all TEE calculations were corrected for the content of isotopes in the drinking water. TEE was calculated by the multi-point method using linear regression as suggested by the International Dietary Energy Consultancy Group (1990). All elimination curves were checked for major or diverging residuals. The $\mathrm{CV}$ for the elimination constants was on average $3.2 \%$ for hydrogen and $2.7 \%$ for oxygen. The mean $\mathrm{N}_{\mathrm{o}}: \mathrm{N}_{\mathrm{d}}$ ratio was 1.033 (SD 0.008; range 1.007-1.049). We used the relationship between pool size of ${ }^{2} \mathrm{H}\left(\mathrm{N}_{\mathrm{d}}\right)$ and pool size of ${ }^{18} \mathrm{O}\left(\mathrm{N}_{\mathrm{o}}\right)$ as a quality measurement for the DLW. The mean food quotient (FQ) determined from the food-frequency questionnaire (FFQ) was 0.85 (SD 0.016; range 0.81-0.89). The individual $\mathrm{N}_{\mathrm{o}}: \mathrm{N}_{\mathrm{d}}$ ratio and $\mathrm{FQ}$ of the participants were used in the calculation of the energy equivalence of the produced $\mathrm{CO}_{2}$ as suggested by the International Dietary Energy Consultancy Group (1990).

\section{Food-frequency questionnaire}

A FFQ was used as the basis of an interview with a registered dietitian (M. S.), lasting between 1 and $2 \mathrm{~h}$. The FFQ was designed to assess the food intake during the last 3 months and based on two 
previously developed FFQ (Lindroos et al. 1993; Andersen et al. 1999). The questionnaire elicited frequencies and consumption of 174 individual food items or constellations of items grouped together according to the typical Norwegian meal pattern. Specifically the consumption of soft drinks and alcoholic beverages, sweet baked goods, cookies, cakes, ice cream, desserts, sweets, chocolate and snacks as nuts, potato crisp and popcorn were asked for. The FFQ also included twenty-one summary questions and seven dietary supplement questions. An atlas of food portions as well as photographs, household measurements and ordinary models of sweets and snacks was used to estimate portion sizes. Particular attention was given to extra layers of bread spread, food eaten during cooking, fat used in frying and extra portions of dinner and dinner leftovers. The FFQ interview was done immediately following the DLW measurement period.

\section{Weighed dietary records}

Participants were provided with food scales and instructed to weigh each individual food item using a digital scaled weight and provide notes on ingredients of composite dishes with approximate quantities. When weighing was not appropriate, the subject used household measurements and pictures to record portion sizes. Forty-nine subjects completed dietary records (DR) for three non-consecutive days. One male subject was not able to complete the DR due to personal problems. The records were done with 3-4d between each recording and all days of the week were about equally represented. On average the DR were completed a mean of 34 (SD 25) d before the DLW measurements.

We assessed eating frequency by counting the number of eating occasions recorded in the DR. An eating occasion was defined as a food or snack (solid or liquid) containing energy with an interval of $>1 \mathrm{~h}$ separating the occasions (Farshchi et al. 2005).

\section{Assessment of eating behaviour}

Forty-nine subjects completed the Norwegian version of the Three Factor Eating Questionnaire. One male refused to fill in the questionnaire. The Three Factor Eating Questionnaire was developed to measure cognitive and behavioural components of eating (Stunkard \& Messick, 1985). The scale contains subscales for restraint (possible scores 0-21), disinhibition (0-16) and hunger $(0-14)$. The restraint subscale assesses the intent to control food intake to achieve and maintain a desired body weight. The disinhibition scale assesses overeating in response to a variety of situations associated with loss of control of food intake, while the hunger subscale assesses subjective feeling of hunger and food cravings.

\section{Definition of under-reporters and non-under-reporters of energy}

Subjects were identified as under-reporters, accurate reporters and over-reporters of energy based on the $95 \%$ confidence limits (CL) of the expected EI:TEE ratio of 1.00 . The $95 \%$ CL between the two measurements were calculated from the published equation (Black \& Cole, 2000):

$$
95 \% \mathrm{CL}= \pm 2 \times \sqrt{ }\left(\left(\mathrm{CV}_{\mathrm{TEE}}\right)^{2}+\left(\mathrm{CV}_{\mathrm{EI}}^{2} / \mathrm{d}\right)\right) .
$$

$\mathrm{CV}_{\mathrm{TEE}}$ for repeated measurements for energy measurements by the DLW method was $8 \%$ (Black \& Cole, 2000). $\mathrm{CV}_{\mathrm{EI}}$ is the within-subject CV for daily intake of energy and $23 \%$ was used (Bingham, 1987). The number of days was 90 for the FFQ and 3 for the DR.

According to this calculation, subjects were classified as underreporters, accurate reporters and over-reporters, depending on how much EI:TEE deviated from the expected ratio of 1.00. Subjects defined as accurate-reporters $\mathrm{FFQ}_{\mathrm{FQ}}$ had an $\mathrm{EI}_{\mathrm{FFQ}}$ :TEE ratio within the $95 \% \mathrm{CL}(0 \cdot 83,1 \cdot 17)$, under-reporters $\mathrm{FFQ}_{\mathrm{FQ}}$ had an $\mathrm{EI}_{\mathrm{FFQ}}$ : TEE ratio below the lower CL $(<0.83)$ and over-reporters ${ }_{\mathrm{FFQ}}$ had an $\mathrm{EI}_{\mathrm{FFQ}}$ :TEE ratio above the upper CL $(>1 \cdot 17)$. Accuratereporters ${ }_{\mathrm{DR}}$ had an $\mathrm{EI}_{\mathrm{DR}}$ :TEE ratio within the $95 \% \mathrm{CL}(0.69$, 1.31), under-reporters ${ }_{\mathrm{DR}}$ had an $\mathrm{EI}_{\mathrm{DR}}$ :TEE ratio below the lower $\mathrm{CL}(<0.69)$ and over-reporters $\mathrm{DR}_{\mathrm{DR}}$ had an $\mathrm{EI}_{\mathrm{DR}}$ :TEE ratio above the upper CL $(>1 \cdot 31)$. According to the FFQ, two males and two females were classified as over-reporters; while, according to the DR, one female was an over-reporter. Because the number of over-reporters was minor, accurate reporters and over-reporters were grouped as non-under-reporters.

\section{Calculations and statistics}

The FFQ and the DR were coded manually for calculations of total energy, energy density, energy-yielding nutrients and food items with a computer program based on the Norwegian food composition table (Rimestad et al. 1995; National Association for Nutrition and Health, 1996). Because of the low median intake of specific foods, we grouped food items into the following categories: fruit, berries, juice and jam; milk; bread; vegetables; boiled potatoes, rice and pasta; fatty meats, minced meat and sausages; chicken and meat with less fat; fish and fish products; oil, butter and margarine; fatty cheese; sweets, desserts and snacks; sugary drinks. The calculated dietary intake of energy assessed by FFQ and DR was compared directly to the estimated TEE from the DLW measurement. Energy density was calculated for the whole diet minus all drinks (coffee, tea, milk, juice, soft drinks and alcoholic beverages).

The results are presented as means and standard deviations, or medians with interquartile ranges (IQR) for non-normally distributed data. Mean and median differences were tested with the unpaired Student's $t$ test and the Mann-Whitney signed rank test, respectively.

Anthropometrics, daily intake of nutrients and food and eating scores for restraint, disinhibition and hunger were correlated with the EI:TEE ratio calculated by the FFQ and the DR. Pearson's correlation coefficients were calculated for normally distributed variables and Spearman's rank correlation coefficients $\left(R_{\mathrm{S}}\right)$ were calculated for skewed variables. Simple regression analyses were conducted to assess the relation of reporting accuracy to percentages of energy from protein, fat, and carbohydrate and food intakes to determine whether there was selective underreporting. Factors that were statistically significant in the univariate analysis were entered into a multiple regression analysis to identify the most important factors correlated to reported accuracy of EI. Because the intake of food is reflected in the calculated diet composition, we chose to enter the reported intake of food instead of diet composition in the multivariate regression analyses.

The tests were considered significant at $P<0 \cdot 05$. Statistical analyses were performed using the StatView 5.0.1 software (SAS Institute Inc., Cary, NC, USA). 


\section{Results}

Characteristics of participants according to sex are shown in Table 1. Subjects had high concentrations of triacylglycerols, diastolic blood pressure and waist circumference in accordance with the inclusion criteria. Restraint and hunger scores were similar for men and women, but women scored higher than men on the disinhibition factor.

\section{Eating characteristics of under-reporters and non-under- reporters}

Relative to TEE, both men and women under-reported EI in both dietary assessment methods. EI among male subjects was underreported by 14.1 (SD 18.9; range -36.0 to 41.6 ) $\%$ according to the FFQ and by 27.9 (SD 14.4; range -3.1 to 51.7 ) \% according to the DR compared with the measured TEE. Female subjects under-reported EI by 20.6 (SD 24.1; range -35.2 to 62.9 ) and 31.0 (SD 22.0; range -44.6 to 69.0 ) $\%$ according to the FFQ and the DR, respectively. No significant difference by sex was seen in the reported EI relative to TEE. More than $50 \%$ of the subjects were classified as under-reporters of EI according to both methods (Table 2).

Anthropometrics, energy expenditure, energy density, daily intakes of energy-yielding nutrients and foods and scores for eating behaviour in under-reporters and non-under-reporters according to the FFQ and DR are shown in Tables 3 and 4, and Tables 5 and 6, respectively. Eating frequency assessed by the DR is also shown in Table 6. According to the DR, under-reporters had a lower energy density of the diet and reported a lower intake of 'sweets, desserts and snacks' and sugary drinks, as was reflected in a higher percentage of energy from protein and a lower percentage of energy from sugar among under-reporters compared with non-under-reporters. However, the reported absolute amount of protein was lower in under-reporters compared with non-under-reporters according to both dietary assessment methods (92.2 (SD 23.0) v. 117.2 (SD 30.9) g; $P=0.0018$ according to the FFQ and 80.7 (SD 23.7) v. 97.5 (SD 20.0) g; $P=0.0116$ according to the DR). Energy-adjusted intake of sweets, desserts and snacks (median) was lower among under-reporters than nonunder-reporters, respectively (7.7 (interquartile range (IQR) 4.910.9) v. 11.0 (IQR 7.6-14.7) $\mathrm{g} / \mathrm{MJ} ; P=0.0275)$ according to the DR. According to the FFQ the same trend was seen, although not statistically significant (11.1 (IQR 7.0-13.7) v. 12.2 (IQR 9.9-14.8) g/MJ; $P=0 \cdot 2256$ ). Sweets, desserts and snacks intake was inversely related to percentage energy from protein according to the FFQ $\left(R_{\mathrm{S}}-0.51 ; P=0.0004\right)$ and the DR $\left(R_{\mathrm{S}}-0.48\right.$; $P=0.0008)$. According to the DR, the energy density of the diet was associated with sweets, desserts and snacks $\left(R_{\mathrm{S}} 0.553\right.$; $P=0.0001)$ and according to the FFQ the association was not significant $\left(R_{\mathrm{S}} 0.272 ; P=0.573\right)$.

No significant differences were seen in eating behaviour scores in under-reporters compared with non-under-reporters, with the exception of restraint scores, which were higher in under-reporters than non-under-reporters according to the DR (Table 5).

During the DLW period, the mean weight change in all participants was 0.1 (SD 1.0; range -3.6 to 1.8 ) $\mathrm{kg}$. No significant weight difference was seen between under-reporters and nonunder-reporters $(0.01$ (SD 0.97) v. $0.22(\mathrm{SD} \mathrm{1.11)} \mathrm{kg} ; P=0.4768$ according to the FFQ and 0.01 (SD 1.12) v. 0.29 (SD 0.82) kg; $P=0.3299$ according to the DR). There was no significant difference in the weight change between under-reporters and nonunder-reporters in the entire 3-month period of the study (1.24 (SD 1.56) v. 1.49 (SD 1.57) kg; $P=0.5769$ according to the FFQ and 1.50 (SD 1.50) v. 1.21 (SD 1.65) $\mathrm{kg}$ according to the DR).

\section{Reporting accuracy}

The relationship of reporting accuracy to anthropometrics, energy density, diet composition, intakes of food and eating behaviour scores is shown in Table 7. According to the FFQ, reporting accuracy was inversely correlated to the percentage energy from protein and positively to the percentage energy from sugar and the energy density of the diet. Accuracy was positively associated with the intake of the following: sweets, desserts and snacks; fatty cheese; bread; milk; oil, butter and margarine. Scores for restraint were inversely and scores for hunger were positively

Table 1. Characteristics of participants* (Mean values and standard deviations)

\begin{tabular}{|c|c|c|c|c|c|}
\hline & \multicolumn{2}{|c|}{ Men $(n$ 23) } & \multicolumn{2}{|c|}{ Women (n 27) } & \multirow[b]{2}{*}{$P$} \\
\hline & Mean & SD & Mean & SD & \\
\hline Age (years) & 44 & 10 & 42 & 11 & 0.5543 \\
\hline Height (m) & 1.82 & 0.07 & 1.69 & 0.06 & $<0.0001$ \\
\hline Weight (kg) & $115 \cdot 1$ & $13 \cdot 8$ & 104.5 & $12 \cdot 1$ & 0.0058 \\
\hline BMI $\left(\mathrm{kg} / \mathrm{m}^{2}\right)$ & 34.6 & 2.9 & $36 \cdot 6$ & 3.4 & 0.0290 \\
\hline Tissue fat $(\%)$ & 41.5 & $7 \cdot 5$ & $53 \cdot 3$ & $5 \cdot 6$ & $<0.0001$ \\
\hline Waist $(\mathrm{cm})$ & $118 \cdot 4$ & $10 \cdot 0$ & $106 \cdot 4$ & $9 \cdot 4$ & $<0.0001$ \\
\hline Hips (cm) & $110 \cdot 0$ & 7.6 & $117 \cdot 6$ & $9 \cdot 6$ & 0.0036 \\
\hline Waist:hip ratio & $1 \cdot 1$ & 0.1 & 0.9 & 0.1 & $<0.0001$ \\
\hline Systolic blood pressure $(\mathrm{mmHg})$ & 128 & 11 & 123 & 15 & 0.1824 \\
\hline Diastolic blood pressure $(\mathrm{mmHg})$ & 85 & 8 & 85 & 10 & 0.9143 \\
\hline Total cholesterol $(\mathrm{mmol} / \mathrm{l})$ & $6 \cdot 2$ & $1 \cdot 1$ & $6 \cdot 2$ & $1 \cdot 3$ & 0.9217 \\
\hline LDL-cholesterol (mmol/l) & $3 \cdot 8$ & 0.7 & $4 \cdot 1$ & $1 \cdot 1$ & 0.4256 \\
\hline HDL-cholesterol (mmol/li) & $1 \cdot 1$ & 0.2 & $1 \cdot 3$ & 0.3 & 0.0044 \\
\hline Triacylglycerols (mmol/l) & $2 \cdot 7$ & 1.6 & 1.9 & 0.8 & 0.0184 \\
\hline Glucose $(\mathrm{mmol} / \mathrm{l})$ & 5.4 & 0.6 & $5 \cdot 3$ & 0.5 & 0.8167 \\
\hline
\end{tabular}

${ }^{*}$ Differences between sexes were tested with unpaired $t$ tests. 
Table 2. Percentage of participants classified as under-reporters, accurate reporters and over reporters of energy intake by the food-frequency questionnaire and the dietary records

\begin{tabular}{|c|c|c|c|c|c|c|}
\hline & \multicolumn{3}{|c|}{ Food-frequency questionnaire ( $n 50)$} & \multicolumn{3}{|c|}{ Dietary records ( $n$ 49) } \\
\hline & Percentage & Male $(n)$ & Female $(n)$ & Percentage & Male $(n)$ & Female $(n)$ \\
\hline Under-reporters of energy & 56 & 12 & 16 & 53 & 11 & 15 \\
\hline Accurate reporters of energy & 36 & 9 & 9 & 45 & 11 & 11 \\
\hline Over-reporters of energy & 8 & 2 & 2 & 2 & 0 & 1 \\
\hline
\end{tabular}

associated with accuracy. According to the DR, the percentage energy from protein and scores for restraint were inversely correlated to accuracy, while the percentage energy from fat, energy density, eating frequencies, intakes of 'sweets, desserts and snacks', sugary drinks, 'fatty meat, minced meat and sausages', and fatty cheese and hunger were positively associated with accuracy. Reporting accuracy was not significantly correlated to educational level $(R 0 \cdot 156 ; P=0.2781)$.

The multiple regression analysis of the reporting accuracy of energy according to the FFQ is shown in Table 8. 'Sweets, desserts and snacks', energy density, fatty cheese, bread, 'oil, butter and margarine', and restraint were entered into the model. 'Sweets, desserts and snacks' and bread $\left(R_{\text {adj }}^{2} 0.46(95 \%\right.$ CI $0.32,0.70)$ ) were significant predictors. The multiple regression analysis of the reporting accuracy of energy according to the DR is shown in Table 9. 'Sweets, desserts and snacks', energy density, sugary drinks, restraint, eating frequency and hunger were entered into the multivariate model and 'sweets, desserts and snacks' and restraint were significant predictors of the variation in the reporting accuracy of energy $\left(R_{\mathrm{adj}}^{2} 0.67(95 \%\right.$ CI $0.54,0.83)$ ). Eating frequency was positively correlated to sweets, desserts and snacks $\left(R_{\mathrm{S}} 0.54 ; P=0.0002\right)$ and sugary drinks $\left(R_{\mathrm{S}} 0.30 ; P=0.0360\right)$. Individual items in the category of sweets, desserts and snacks showed the same trends as the entire category (data not shown).

\section{Discussion}

The present study focused on subjects with the metabolic syndrome or two risk factors for the metabolic syndrome. The reported consumption of sweets, desserts and snacks was lower among under-reporters than non-under-reporters and showed a significant association with reporting accuracy according to both methods of dietary assessment (FFQ and DR) in the multiple regression analyses. In addition, bread consumption assessed by the FFQ was a significant contributor to reporting accuracy. Dietary restraint was an additional significant contributor to accuracy assessed by DR.

About half of this obese population with metabolic risk factors under-reported EI. This finding is in accordance with the Observing Protein and Energy Nutrition (OPEN) study that included 484 subjects of whom 142 had BMI $\geq 30 \mathrm{~kg} / \mathrm{m}^{2}$, and $57 \%$ of the

Table 3. Anthropometry, energy expenditure, energy intake, energy density, macronutrient composition and eating scores in under-reporters (UR) and non-under-reporters (non-UR) according to the food-frequency questionnaire*

(Mean values and standard deviations)

\begin{tabular}{|c|c|c|c|c|c|}
\hline & \multicolumn{2}{|c|}{ UR ( $n 28)$} & \multicolumn{2}{|c|}{ Non-UR (n 22) } & \multirow[b]{2}{*}{$P$} \\
\hline & Mean & SD & Mean & SD & \\
\hline Tissue fat (\%) & $49 \cdot 1$ & $8 \cdot 7$ & $46 \cdot 2$ & $9 \cdot 0$ & 0.2489 \\
\hline Waist:hip ratio & 1.0 & 0.1 & 1.0 & 0.1 & 0.8777 \\
\hline BMI $\left(\mathrm{kg} / \mathrm{m}^{2}\right)$ & $36 \cdot 3$ & 3.6 & $35 \cdot 0$ & $2 \cdot 7$ & 0.1522 \\
\hline Total energy expenditure $(\mathrm{kJ} / \mathrm{d})$ & 14038 & 2464 & 13819 & 2524 & 0.7594 \\
\hline $\operatorname{RMR}(k J / d)$ & 7606 & 898 & 7452 & 1178 & 0.6016 \\
\hline Physical activity level† & 1.84 & 0.17 & 1.86 & 0.21 & 0.7401 \\
\hline Energy intake $(\mathrm{kJ} / \mathrm{d})$ & 9573 & 2571 & 13938 & 3723 & $<0.0001$ \\
\hline Energy intake:total energy expenditure & 0.68 & 0.12 & 1.01 & 0.18 & $<0.0001$ \\
\hline Energy density $(\mathrm{kJ} / \mathrm{g})$ & 6.49 & 1.06 & $7 \cdot 35$ & $2 \cdot 13$ & 0.0699 \\
\hline \multicolumn{6}{|l|}{ Diet composition (\% energy) } \\
\hline Fat & 34.5 & 3.9 & $35 \cdot 5$ & $5 \cdot 9$ & 0.4793 \\
\hline Protein & $16 \cdot 3$ & $2 \cdot 4$ & $14 \cdot 8$ & $2 \cdot 4$ & 0.0287 \\
\hline Carbohydrate & $45 \cdot 2$ & $5 \cdot 5$ & $46 \cdot 6$ & $7 \cdot 0$ & 0.4349 \\
\hline Sucrose & $5 \cdot 4$ & $2 \cdot 9$ & $8 \cdot 6$ & $8 \cdot 3$ & 0.0698 \\
\hline Alcohol & $2 \cdot 7$ & $2 \cdot 9$ & $2 \cdot 3$ & 4.5 & 0.7038 \\
\hline \multicolumn{6}{|l|}{ Eating scoresł } \\
\hline Restraint & 8.5 & $4 \cdot 8$ & $6 \cdot 3$ & 3.9 & 0.0929 \\
\hline Disinhibition & $8 \cdot 1$ & $3 \cdot 2$ & $8 \cdot 2$ & $3 \cdot 2$ & 0.9180 \\
\hline Hunger & $5 \cdot 3$ & $2 \cdot 9$ & $6 \cdot 0$ & 3.4 & 0.4625 \\
\hline
\end{tabular}

* Differences between UR and non-UR were tested with unpaired $t$ tests.

†Physical activity level is calculated by dividing total energy expenditure by RMR

$\ddagger$ The results of one male were missing. 
Table 4. Intake of food in under-reporters (UR) and non-under-reporters (non-UR) according to the food-frequency questionnaire*

(Medians and interquartile ranges)

\begin{tabular}{|c|c|c|c|c|c|}
\hline \multirow[b]{2}{*}{ Food (g/d) } & \multicolumn{2}{|c|}{ UR ( $n$ 28) } & \multicolumn{2}{|c|}{ Non-UR ( $n$ 22) } & \multirow[b]{2}{*}{$P$} \\
\hline & Median & IQR & Median & IQR & \\
\hline Fruit, berries, juice and jam & 246 & $140-387$ & 305 & $78-614$ & 0.6182 \\
\hline Milk & 202 & $55-338$ & 302 & $154-604$ & 0.0451 \\
\hline Bread & 152 & $114-180$ & 213 & $125-286$ & 0.0837 \\
\hline Vegetables & 190 & $116-269$ & 197 & $123-332$ & 0.8298 \\
\hline Boiled potatoes, rice and pasta & 153 & $119-210$ & 190 & $119-208$ & 0.4117 \\
\hline Fatty meat, minced meat and sausages & 71 & $47-82$ & 66 & $32-161$ & 0.9820 \\
\hline Chicken and meat with less fat & 69 & $43-103$ & 68 & $28-93$ & 0.5909 \\
\hline Fish and fish products & 58 & $36-92$ & 82 & $28-105$ & 0.8298 \\
\hline Oil, butter and margarine & 50 & $28-67$ & 67 & $29-91$ & 0.1112 \\
\hline Fatty cheese & 24 & $9-48$ & 35 & $18-72$ & 0.1594 \\
\hline Sweets, desserts and snacks & 100 & $64-135$ & 161 & $121-196$ & 0.0008 \\
\hline Sugary drinks & 63 & $0-211$ & 150 & $18-378$ & 0.2146 \\
\hline
\end{tabular}

IQR, interquartile range.

*Differences in reported intake of food in UR and non-UR were tested with the Mann-Whitney signed rank test.

Table 5. Anthropometry, energy expenditure, energy intake, energy density, macronutrient composition and eating scores in under-reporters (UR) and non-under-reporters (non-UR) according to the dietary records*

(Mean values and standard deviations)

\begin{tabular}{|c|c|c|c|c|c|}
\hline & \multicolumn{2}{|c|}{ UR $(n 28)$} & \multicolumn{2}{|c|}{ Non-UR ( $n$ 22) } & \multirow[b]{2}{*}{$P$} \\
\hline & Mean & SD & Mean & SD & \\
\hline Tissue fat (\%) & $49 \cdot 2$ & $8 \cdot 2$ & $45 \cdot 9$ & $8 \cdot 7$ & 0.2613 \\
\hline Waist:hip ratio & $1 \cdot 0$ & 0.1 & $1 \cdot 0$ & 0.1 & 0.7869 \\
\hline $\mathrm{BMI}\left(\mathrm{kg} / \mathrm{m}^{2}\right)$ & 36.4 & $3 \cdot 2$ & $35 \cdot 0$ & 3.4 & 0.1531 \\
\hline Total energy expenditure (kJ/d) & 14107 & 2791 & 13613 & 2021 & 0.4866 \\
\hline $\operatorname{RMR}(\mathrm{kJ} / \mathrm{d})$ & 7598 & 990 & 7394 & 1022 & 0.4836 \\
\hline Physical activity level† & 1.85 & 0.22 & 1.84 & 0.15 & 0.9143 \\
\hline Energy intake $(\mathrm{kJ} / \mathrm{d})$ & 8071 & 1999 & 12756 & 4112 & $<0.0001$ \\
\hline Energy intake: total energy expenditure & 0.57 & 0.09 & 0.85 & 0.16 & $<0.0001$ \\
\hline Energy density $(\mathrm{kJ} / \mathrm{g})$ & $6 \cdot 70$ & $1 \cdot 34$ & $7 \cdot 90$ & 1.59 & 0.0064 \\
\hline \multicolumn{6}{|l|}{ Diet composition (\% energy) } \\
\hline Fat & $34 \cdot 8$ & 6.5 & $36 \cdot 2$ & $5 \cdot 5$ & 0.4396 \\
\hline Protein & $16 \cdot 8$ & 3.3 & $14 \cdot 7$ & $2 \cdot 3$ & 0.0151 \\
\hline Carbohydrate & $46 \cdot 3$ & 7.5 & $46 \cdot 6$ & $6 \cdot 2$ & 0.9789 \\
\hline Sucrose & 4.9 & 3.3 & $9 \cdot 3$ & $7 \cdot 0$ & 0.0063 \\
\hline Alcohol & $1 \cdot 3$ & $2 \cdot 8$ & $2 \cdot 1$ & 4.5 & 0.4819 \\
\hline \multicolumn{6}{|l|}{ Eating scoresł } \\
\hline Restraint & $9 \cdot 0$ & $5 \cdot 0$ & $6 \cdot 1$ & 3.5 & 0.0285 \\
\hline Disinhibition & $7 \cdot 7$ & $3 \cdot 2$ & 8.9 & 3.0 & 0.2184 \\
\hline Hunger & $4 \cdot 8$ & $2 \cdot 9$ & $6 \cdot 4$ & 3.2 & 0.0769 \\
\hline
\end{tabular}

* Differences between UR and non-UR were tested with unpaired $t$ tests.

†Physical activity level is calculated by dividing total energy expenditure by RMR.

$\ddagger$ The results of one male were missing.

obese participants were classified as under-reporters of energy according to the FFQ (Subar et al. 2003). In the present study, men under-reported EI by $14 \%$ and women by $21 \%$ according to the FFQ. According to the DR, men and women under-reported EI by 28 and $31 \%$, respectively. In comparison, Goris et al. (2000) found a $37 \%$ under-reporting of energy by male subjects with a BMI similar to that of subjects in the present study.

A novel finding in the present study was that consumption of bread according to the FFQ was a significant contributor to accuracy. This finding may be partly explained by the association between bread consumption and an irregular or frequent meal pattern. In Norway bread-based meals are typically consumed two to three times per $d$. In addition, bread is often consumed as a between-meal snack. The extra bread eaten at irregular meals and snacks may be forgotten or not reported. In contrast, consumption of bread was not associated with accuracy measured by DR. However, under eating may be a major problem with $\mathrm{DR}$ as discussed below.

Consumption of sweets, desserts and snacks was robustly associated with reporting accuracy, and was the only multivariate determinant of accuracy in addition to bread consumption according to the FFQ. These two variables explained almost half of the multivariate variance in accuracy. Likewise, reported intake of sweets, desserts and snacks was associated with accuracy 
Table 6. Daily intake of food and eating frequency in under-reporters (UR) and non-under-reporters (non-UR) according to the dietary records*

(Medians and interquartile ranges)

\begin{tabular}{|c|c|c|c|c|c|}
\hline \multirow[b]{2}{*}{ Food $(g / d)$} & \multicolumn{2}{|c|}{ UR ( $n$ 28) } & \multicolumn{2}{|c|}{ Non-UR $(n$ 22) } & \multirow[b]{2}{*}{$P$} \\
\hline & Median & IQR & Median & IQR & \\
\hline Fruit, berries, juice and jam & 253 & $110-354$ & 195 & $75-388$ & 0.9680 \\
\hline Milk & 126 & $0-292$ & 127 & $54-370$ & 0.5090 \\
\hline Bread & 154 & $121-213$ & 198 & $121-235$ & 0.3890 \\
\hline Vegetables & 115 & $75-149$ & 103 & $57-158$ & 0.8100 \\
\hline Boiled potatoes, rice and pasta & 118 & $85-168$ & 100 & $58-202$ & 0.6025 \\
\hline Fatty meat, minced meat and sausages & 52 & $8-121$ & 119 & $38-164$ & 0.1158 \\
\hline Chicken and meat with less fat & 71 & $20-100$ & 34 & $9-63$ & 0.2033 \\
\hline Fish and fish products & 44 & $0-137$ & 47 & $4-122$ & 0.7800 \\
\hline Oil, butter and margarine & 31 & $17-56$ & 40 & $21-79$ & 0.2662 \\
\hline Fatty cheese & 23 & $13-34$ & 28 & $8-47$ & 0.3781 \\
\hline Sweets, deserts and snacks & 61 & $38-93$ & 128 & $108-185$ & 0.0002 \\
\hline Sugary drinks & 0 & $0-110$ & 167 & $0-335$ & 0.0057 \\
\hline Eating frequency (times/d) & $4 \cdot 7$ & $3 \cdot 3-5 \cdot 0$ & $5 \cdot 0$ & $4 \cdot 3-6 \cdot 0$ & 0.2333 \\
\hline
\end{tabular}

IQR, interquartile range.

*Differences in reported intake of food in UR and non-UR were tested with the Mann-Whitney signed rank test.

according to the DR. The finding of low reports of sweets, desserts and snacks is in accordance with a number of previous studies. In a study by Livingstone et al. (1990), snacks were named as the most onerous and irritating aspect of the recording

Table 7. Relation of accuracy according to the food-frequency questionnaire (FFQ) and dietary records (DR) to energy density, macronutrient composition, food, eating frequency and eating scores

(Correlation coefficients)

\begin{tabular}{|c|c|c|c|c|}
\hline & \multicolumn{2}{|c|}{ FFQ } & \multicolumn{2}{|c|}{ DR } \\
\hline & El:TEE & $P$ & El:TEE & $P$ \\
\hline Energy density* & 0.406 & 0.0034 & 0.537 & $<0.0001$ \\
\hline \multicolumn{5}{|l|}{ Diet composition (\% energy) ${ }^{\star}$} \\
\hline Fat & 0.224 & 0.118 & 0.292 & 0.0414 \\
\hline Protein & -0.438 & 0.0015 & -0.403 & 0.0041 \\
\hline Carbohydrate & 0.051 & 0.7273 & 0.191 & 0.1882 \\
\hline Sucrose & 0.283 & 0.0462 & 0.251 & 0.0824 \\
\hline Alcohol & 0.049 & 0.7342 & 0.220 & 0.1283 \\
\hline \multicolumn{5}{|l|}{ Food $(g / d) \dagger$} \\
\hline Fruit, berries, juice and jam & 0.135 & 0.3445 & 0.040 & 0.7826 \\
\hline Milk & 0.333 & 0.0197 & 0.007 & 0.9630 \\
\hline Bread & 0.387 & 0.0067 & 0.262 & 0.0694 \\
\hline Vegetables & 0.024 & 0.8690 & -0.005 & 0.9735 \\
\hline $\begin{array}{l}\text { Boiled potatoes, rice and } \\
\text { pasta }\end{array}$ & 0.201 & 0.1584 & -0.013 & 0.9286 \\
\hline $\begin{array}{l}\text { Fatty meat, minced meat } \\
\text { and sausages }\end{array}$ & 0.218 & 0.1270 & 0.300 & 0.0380 \\
\hline $\begin{array}{l}\text { Chicken and meat with less } \\
\text { fat }\end{array}$ & -0.093 & 0.5166 & -0.237 & 0.1009 \\
\hline Fish and fish products & 0.114 & 0.4250 & 0.002 & 0.9917 \\
\hline Oil, butter and margarine & 0.379 & 0.0080 & 0.256 & 0.0758 \\
\hline Fatty cheese & 0.398 & 0.0053 & 0.295 & 0.0407 \\
\hline $\begin{array}{l}\text { Sweets, desserts and } \\
\text { snacks }\end{array}$ & 0.513 & 0.0003 & 0.698 & $<0.0001$ \\
\hline Sugary drinks & 0.214 & 0.1336 & 0.490 & 0.0007 \\
\hline Eating frequency (times/d) $\dagger$ & NA & NA & 0.360 & 0.0125 \\
\hline \multicolumn{5}{|l|}{ Eating scores ${ }^{\star}$} \\
\hline Restraint & -0.373 & 0.0098 & -0.388 & 0.0140 \\
\hline Disinhibition & 0.038 & 0.7913 & 0.118 & 0.4203 \\
\hline Hunger & 0.301 & 0.0369 & 0.318 & 0.0304 \\
\hline
\end{tabular}

El, energy intake; TEE, total energy expenditure, NA, not analysed.

* Correlation coefficients were calculated with Pearson's correlations.

tCorrelation coefficients were calculated with Spearman rank correlations. procedure and subjects admitted having omitted or simplified some measurements. In a Norwegian survey, Johansson et al. (1998) reported that under-reporters had a lower intake of cakes, potato chips, chocolate, sweets and sugar-containing soft drinks. Likewise, among non-obese women, Bingham et al. (1995) found a lower intake of breakfast cereals, cakes and sugars and confectionery in under-reporters compared with accurate reporters and consumption of sugar and sweet foods was also lower in under-reporters in two other large surveys (Rothenberg et al. 1997; Cook et al. 2000). Based on data from a number of studies Heitmann \& Lissner (1995) concluded that snack-type foods might preferably be forgotten or suppressed when obese subjects omit food items in dietary reporting. This notion has been directly substantiated in an elegant study. Poppitt et al. (1998) covertly measured the food intake of obese and nonobese women confined to a metabolic facility and allowed ad libitum food intake. Food consumed during a meal was reported accurately, but the between-meal snack food was under-reported by over one-third. With the exception of the study by Livingstone et al. (1990), under-reporters were identified according to calculated EI:RMR ratios, $\mathrm{N}$ excretion or directly measured in a metabolic facility. One strength of the present study is that we quantified the contribution of under-reporting of sweets, desserts and snacks to accuracy in free-living, obese subjects with the DLW method according to both the DR and the FFQ.

Table 8. Multiple regression analyses of reporting accuracy of energy according to the food-frequency questionnaire*

(Standardised regression coefficients with their standard errors)

\begin{tabular}{lrcc}
\hline & $\beta$ & SE & $P$ \\
\hline Sweets, desserts and snacks & 0.354 & 0.0002 & 0.0043 \\
Energy density & 0.031 & 0.0170 & 0.8113 \\
Bread & 0.380 & 0.0003 & 0.0163 \\
Fatty cheese & 0.093 & 0.0010 & 0.4434 \\
Oil, butter and margarine & 0.139 & 0.0010 & 0.3022 \\
Restraint & -0.079 & 0.0060 & 0.5159
\end{tabular}

* Reporting accuracy is indicated by the energy intake:total energy expenditure ratio. 
Table 9. Multiple regression analyses of reporting accuracy of energy according to the dietary records*

(Standardised regression coefficients and their standard errors)

\begin{tabular}{lrrr}
\hline & $\beta$ & SE & \multicolumn{1}{c}{$P$} \\
\hline Sweets, desserts and snacks & 0.612 & 0.0002 & $<0.0001$ \\
Energy density & 0.053 & 0.0130 & 0.6298 \\
Sugary drinks & 0.104 & 0.0001 & 0.1508 \\
Restraint & -0.212 & 0.0040 & 0.0444 \\
Eating frequency & 0.154 & 0.0170 & 0.1450 \\
Hunger & 0.005 & 0.0060 & 0.9610 \\
\hline
\end{tabular}

${ }^{*}$ Reporting accuracy is indicated by the energy intake:total energy expenditure ratio.

Despite a strong statistical association between reporting accuracy and sweets, desserts and snacks in the multivariate analyses, the difference in reported intake of sweets, desserts and snacks was only $60 \mathrm{~g} / \mathrm{d}$ representing about $1 \mathrm{MJ} / \mathrm{d}$. The energy difference between under-reporters and non-under-reporters was $4.5 \mathrm{MJ} / \mathrm{d}$, thus less than one-quarter was accounted for. It appears that the underestimation is more general as seen in the energy density of the diet, at least according to the DR, and in the macronutrient composition. The percentage energy from protein was higher but the actual intake of protein was lower among under-reporters than non-under-reporters. Excretion of urinary $\mathrm{N}$ also indicated that protein intake was lower among under-reporters of energy (data not shown).

The percentage of energy from protein in the diet was strongly inversely related to the reported intake of sweets, desserts and snacks (data not shown). This and other studies (Heitmann \& Lissner, 1995; Pryer et al. 1997; Livingstone \& Black, 2003) suggest that when sweet and fatty foods are under-reported, the percentage of energy from protein increases. In the largest study using urinary $\mathrm{N}$ and DLW methodologies, protein density was similar for men, but slightly overestimated for women (Subar et al. 2003). Heitmann \& Lissner (1995) found a positive association between under-reporting of protein (and total energy) and the degree of obesity among 323 lean and obese men and women. Compared with total energy, protein was over-reported by the obese subjects. Other studies have reported preferential under-reporting of fat (Bingham et al. 1995; Macdiarmid et al. 1998; Goris et al. 2000). Discrepancies between the studies may be explained by differences between populations due to different cultural attitudes or habits, temporal trends, chance or other factors. What foods are considered not healthy, and thus are under-reported, may be affected by societal expectations and messages from the media (Blundell, 2000). In the present study involving obese individuals with characteristics of the metabolic syndrome we speculate that under-reporters may be prone to under-report carbohydrate and fatty food used as sweets, desserts and snacks because of the influence of ongoing debates about low-glycaemic-index diets.

The optimal number of eating occasions to facilitate weight reduction has been debated and it has long been believed that a 'nibbling meal pattern' could be beneficial for the purpose of weight reduction. However, a recent review concluded that weight loss was not facilitated by a high meal frequency (Bellisle, 2004). An association between frequent snacking and EI was also seen in a Swedish study among 4259 obese subjects (Bertéus Forslund et al. 2005). Our findings tend to support these findings since reported energy was, not surprisingly, related to the frequency of eating occasions. However, we did not find a statistically significant difference between the frequency of eating between under-reporters and non-under-reporters. The same was also seen in a study by Livingstone et al. (1990), and may be due to small sample size, which is also a limitation of the present study.

Dietary restraint, the self-imposed practice of consciously attempting to restrict EI with the purpose of preventing weight gain or promoting weight loss, is a common determinant of accuracy (Bathalon et al. 2000), though some conflicting data have been reported. For example, Taren et al. (1999) found no association between restraint and reporting accuracy in overweight individuals using 3 d DR to assess reported EI. Lindroos et al. (1997) found strong associations between EI, disinhibition and hunger, but a weaker association between EI and restraint in obese women. However, reporting accuracy was not considered in that study. In the OPEN study, restrained eating predicted reporting accuracy only when EI was assessed by the $24 \mathrm{~h}$ recall and only among men (Tooze et al. 2004). Furthermore, Bingham et al. (1995) could not differentiate restrained eating from the known effects of obesity on reporting accuracy. In a simple comparison of under-reporters and non-under-reporters, the present study clearly showed that under-reporters in this population had higher dietary restraint scores and restraint was a significant predictor of accuracy according to the DR. Dietary restraint did not contribute significantly to accuracy according to the FFQ. Hunger scores were associated with accuracy in the univariate but not in the final multiple analyses. Intercollinearity between several of the measured variables may explain these observations. Scores for restraint were inversely associated with the consumption of bread, milk and 'oil, butter and margarine' according to the FFQ (data not shown). Of these variables, bread consumption significantly contributed to accuracy in the multivariate analyses.

\section{Methodological issues}

When using DLW as an objective measure of EI, we assume that the subjects were in energy balance over the period of the measurement. The weight change during the DLW period was minor and in accordance with the weight change seen in the Dutch men (Goris et al. 2000). We could have adjusted for the weight change in the calculations, but according to the International Dietary Energy Consultancy Group (1990) the difficulty of accurately estimating change in body composition over the short period of DLW measurement is such that little advantage is gained. We could have adjusted for the increase in weight during the 3-month period resulting in a greater degree of underestimation. However, the 3-month study period that included holidays may not adequately represent long-term weight change. The DLW measurement was done during $14 \mathrm{~d}$ and may not measure the actual long-term energy expenditure (Livingstone \& Black, 2003).

In the calculations of the TEE, we used the individually calculated FQ from the reported intakes according to the FFQ. The under-reporting of carbohydrate could be a concern. However, this probably does not affect the energy calculations because of the high homogeneity of FQ. Fat and carbohydrate intake may vary over a fairly wide range and still the variation in FQ is small (Black et al. 1986). The mean FQ was 0.85 in 
the present study, in agreement with a typically Western diet (Black et al. 1986).

While the FFQ method is prone to under-reporting due to difficulties in remembering eating occasions and estimating portions sizes, under-reporting according to weighed DR may be due both to under-eating and under-recording. We are not able to differentiate between under-eating and under-reporting because a $3 \mathrm{~d}$ food record has too short a time period to follow weight changes. It may be that subjects with high scores for dietary restraint actually under-eat when they record food intake to achieve weight reduction, but it has also been shown that restrained eaters as a group do not report all food they consume (Bathalon et al. 2000).

Dietary restraint became less obvious in the FFQ that covers a much longer time period including holiday seasons for almost all the participants, and most individuals do not restrict eating during holidays. Limitations of the present study were that we did not collect data on the temporal distribution of eating. Furthermore, the DR was collected for only $3 \mathrm{~d}$ and was done a mean of $34 \mathrm{~d}$ before the DLW measurement period. We chose the $3 \mathrm{~d}$ DR to minimise the burden on the participants in accordance with the suggestion by Trabulsi \& Schoeller (2001), that in subjects defined as dietary resistant and obese, any precision gained through a long dietary recording period is outweighed by a larger magnitude of under-reporting. To minimise the burden of the participants was also the reason for obtaining the DR before the DLW measurement period. However, the results of the DR were largely in accordance with the results of the FFQ that covered the DLW measurement period.

In contrast to others (Johansson et al. 1998; Cook et al. 2000), we did not find any relationship between sex or education level and reporting accuracy. This may be due to the limited size of our sample or to differences between populations. Furthermore, in our sample of obese individuals, BMI, percentage of body fat and fat distribution did not predict reporting accuracy. This may be due to the small variation of BMI or that BMI levels out as a predictor for reporting accuracy of energy at BMI levels above $35 \mathrm{~kg} / \mathrm{m}^{2}$ as was observed in the OPEN study (Tooze et al. 2004). The study included only non-smokers and may not be applicable to obese smokers.

\section{Implications}

An understanding of the foods and meal patterns that are associated with errors in self-reported data is critical. Individuals often report their usual dietary intake and forget to report extra meals and snacks or more frequent eating patterns. These items must be particularly emphasised in dietary interviews. It was not our objective to determine which of the dietary assessment methods showed superior accuracy in this obese sample. However, it seems that the FFQ is less influenced by the restraint eating behaviour, while the DR may be an important tool to achieve change in eating behaviour because of increased attention. Because of their high risk, obese subjects with the metabolic syndrome or risk factors for the metabolic syndrome are prime targets for dietary advice to achieve weight reduction. While weight-stable, individuals that report high dietary restraint, low consumption of bread, sweets, desserts and snacks and a low frequency of eating may require particular attention when a dietary assessment is conducted.

\section{Acknowledgements}

We thank Bo-Egil Hustvedt for the RMR measurements, Tor Ole Klemsdal for some of the medical examinations and Lars Ellegård and the staff at the Department of Clinical Nutrition at Sahlgrenska University Hospital, Sweden for the DLW analyses. We also thank the subjects who took part in the study. Both authors contributed to the development of the protocol and wrote the manuscript. M. S. developed the FFQ, performed all the dietary assessments and analysed the data. None of the authors had any personal or financial conflicts of interest.

\section{References}

Andersen LF, Solvoll K, Johansson LR, Salminen I, Aro A \& Drevon CA (1999) Evaluation of a food frequency questionnaire with weighed records, fatty acids, and alpha-tocopherol in adipose tissue and serum. Am J Epidemiol 150, 75-87.

Bathalon GP, Tucker KL, Hays NP, Vinken AG, Greenberg AS, McCrory MA \& Roberts SB (2000) Psychological measures of eating behavior and the accuracy of 3 common dietary assessment methods in healthy postmenopausal women. Am J Clin Nutr 71, 739-745.

Bellisle F (2004) Impact of the daily meal pattern on energy balance. Scan J Nutr 48, 114-118.

Bertéus Forslund H, Torgerson JS, Sjöström L \& Lindroos AK (2005) Snacking frequency in relation to energy intake and food choice in obese men and women compared to a reference population. Int $J$ Obes 29, 711-719.

Bingham S (1987) The dietary assessment of individuals: methods, accuracy, new techniques and recommendations. Nutr Abst Rev 57, 705-742.

Bingham SA, Cassidy A, Cole TJ, et al. (1995) Validation of weight records and other methods of dietary assessment using the $24 \mathrm{~h}$ urine nitrogen technique and other biological markers. $\mathrm{Br} J$ Nutr 73, $531-550$.

Black AE \& Cole TJ (2000) Within- and between-subject variation in energy expenditure measured by the doubly-labelled water technique: implications for validating reported dietary energy intake. Eur J Clin Nutr 54, 386-394.

Black AE, Prentice AM \& Coward WA (1986) Use of food quotients to predict respiratory quotients for the doubly-labelled water method of measuring energy expenditure. Hum Nutr Clin Nutr 40C, 381-391.

Blundell JE (2000) What foods do people habitually eat? A dilemma for nutrition, an enigma for psychology. Am J Clin Nutr 71, 3-5.

Braam LA, Ocke MC, Bueno-de-Mesquita HB \& Seidell JC (1998) Determinants of obesity related under-reporting of energy intake. Am J Epidemiol 147, $1081-1086$.

Caan B, Ballard-Barbash R, Slattery ML, et al. (2004) Low energy reporting may increase in intervention participants enrolled in dietary intervention trials. J Am Diet Assoc 104, 357-366.

Cook A, Pryer J \& Shetty P (2000) The problem of accuracy in dietary surveys. Analysis of the over 65 UK National Diet and Nutrition Survey. J Epidemiol Community Health 54, 611-616.

Dallongeville J, Marécaux N, Fruchart J-C \& Amouyel P (1998) Cigarette smoking is associated with unhealthy patterns of nutrient intake: a meta-analysis. J Nutr 128, 450-457.

Expert Panel on Detection, Evaluation, and Treatment of High Blood Cholesterol in Adults (2001) Executive summary of the third report of the National Cholesterol Education Program (NCEP) Expert Panel on Detection, Evaluation, and Treatment of high blood cholesterol in adults (Adult Treatment Panel III). JAMA 285, 2486-2497.

Farshchi HR, Taylor MA \& Macdonald IA (2005) Beneficial metabolic effects of regular meal frequency on dietary thermogenesis, insulin sensitivity, and fasting lipid profiles in healthy obese women. Am J Clin Nutr 81, 16-24. 
Goris AHC, Westerterp-Platenga MS \& Westerterp K (2000) Undereating and underrecording of habitual food intake in obese men: selective under-reporting of fat intake. Am J Clin Nutr 71, 130-134.

Heitmann BL \& Lissner L (1995) Dietary under-reporting by obese individuals - is it specific or non-specific? BMJ 311, 986-989.

Hill RJ \& Davies PSW (2001) The validity of self-reported energy intake as determined using the doubly labelled water technique. Br J Nutr $\mathbf{8 5}$, $415-430$.

International Dietary Energy Consultancy Group (1990) The Doublylabeled Water Method for Measuring Energy Expenditure. Technical Recommendations for Use in Humans. Vienna: International Atomic Energy Agency.

Johansson L, Solvoll K, Bjørneboe GE \& Drevon CA (1998) Under- and overreporting of energy intake related to weight status and lifestyle in a nationwide sample. Am J Clin Nutr 68, 266-274.

Lindroos AK, Lissner L, Mathiassen M, Karlsson J, Sullivan M, Bengtsson C \& Sjöström L (1997) Dietary intake in relation to restrained eating, disinhibition and hunger in obese and nonobese Swedish women. Obes Res 5, 175-182.

Lindroos AK, Lissner L \& Sjöström L (1993) Validity and reproducibility of a self-administered dietary questionnaire in obese and non-obese subjects. Eur J Clin Nutr 47, 461-481.

Lissner L (2002) New approaches to assessing diets of diverse populations. Measuring food intake in studies of obesity. Part D. Public Health Nutr 5, 889-892.

Lissner L, Heitmann BL \& Lindroos AK (1998) Measuring intake in freeliving human subjects: a question of bias. Proc Nutr Soc 57, 333-339.

Livingstone MBE \& Black AE (2003) Markers of the validity of reported energy intake. J Nutr 133, 895S-920S.

Livingstone MBE, Prentice AM, Strain JJ, Coward WA, Black AE, Barker ME, McKenna PG \& Whitehead RG (1990) Accuracy of weighed dietary records in studies of diet and health. BMJ 300, 708-712.

Macdiarmid JI, Vail A, Cade JE \& Blundell JE (1998) The sugar-fat relationship revisited: differences in consumption between men and women of varying BMI. Int J Obes Relat Metab Disord 22, 1053-1061.

National Association for Nutrition and Health (1996) MAT PA DATA 3.0 for WINDOWS. Oslo: National Association for Nutrition and Health.

Poppitt SD, Swann D, Black AE \& Prentice AM (1998) Assessment of selective under-reporting of food intake by both obese and non-obese women in a metabolic facility. Int J Obes 22, 303-311.

Prentice AM, Black AE, Coward WA \& Cole TJ (1996) Energy expenditure in overweight and obese adults in affluent societies: an analysis of 319 doubly-labelled water measurements. Eur J Clin Nutr 50, 93-97.

Prentice AM, Black AE, Coward WA, Davies HL, Goldberg GR, Murgatroyd PR, Ashford J, Sawyer M \& Whitehead RG (1986) High levels of energy expenditure in obese women. Br Med J (Clin Res Ed) 292, 983-987.

Pryer JA, Vrijheid M, Nichols R \& Elliot P (1997) Who are the "low energy reporters" in the Dietary and Nutritional Survey of British Adults? Int J Epidemiol 26, 146-153.

Rimestad AH, Blaker B, Færden K, Flåten A-M, Lund-Larsen K, Nordbotten K \& Trygg K (1995) Den Store Matvaretabellen. Oslo: National Nutrition Council.

Rosell MS, Hellénius MLB, de Faire UH \& Johansson GK (2003) Associations between diet and the metabolic syndrome vary with the validity of dietary intake data. Am J Clin Nutr 78, 84-90.

Rothenberg E, Bosaeus I \& Steen B (1997) Evaluation of energy intake estimated by a diet history in three free-living 70 year old populations in Gothenburg, Sweden. Eur J Clin Nutr 51, 60-66.

Slinde F, Ellegård L, Grønberg AM, Larsson S \& Rossander-Hultén L (2003) Total energy expenditure in underweight patients with severe chronic obstructive pulmonary disease living at home. Clin Nutr 22, $159-165$.

Stunkard AJ \& Messick S (1985) The Three Factor Eating Questionnaire to measure dietary restraint, disinhibition and hunger. J Psychosom Res 29, $71-83$.

Subar AF, Kipnis V, Troiano R, et al. (2003) Using intake biomarkers to evaluate the extent of dietary misreporting in a large sample of adults: The OPEN study. Am J Epidemiol 158, 1-13.

Taren DL, Tobar M, Hill A, Howell W, Shisslak C, Bell I \& Ritenbaug C (1999) The association of energy intake bias with psychological scores of women. Eur J Clin Nutr 53, 570-578.

Tonstad S, Gorbitz C, Sivertsen M \& Ose L (1999) Under-reporting of dietary intake by smoking and nonsmoking subjects counseled for hypercholesterolaemia. J Intern Med 245, 337-344.

Tooze JA, Subar AF, Thompson FE, Troiano R, Schatzkin A \& Kipnis V (2004) Psychosocial predictors of energy under-reporting in a large doubly labelled water study. Am J Clin Nutr 79, 795-804.

Trabulsi L \& Schoeller DA (2001) Evaluation of dietary assessment instruments against doubly labeled water, a biomarker of habitual energy intake. Am J Endocrinol Metab 281, E891-E899.

Tuomilehto J, Lindstrom J, Erikkson JG, et al. (2001) Prevention of type 2 diabetes mellitus by changes in lifestyle among subjects with impaired glucose tolerance. $N$ Engl J Med 344, 1343-1350. 